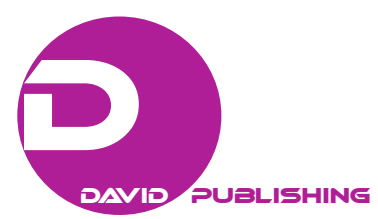

\title{
Effect of Normative and Socioeconomic Power Bases on Japanese Marital Decision-Making Authority
}

\author{
Zsolt Varga, Wirawan Dony Dahana, Sotaro Katsumata \\ Osaka University, Osaka, Japan
}

\begin{abstract}
According to normative-resource theory, the balance of marital power is influenced by the effect of socioeconomic resources and subcultural expectations. The purpose of our study is to empirically test the effects of Japanese married individuals' comparative socioeconomic variables-education, age, occupation status, personal income, family income, urban/rural living area, years married, and the presence/number of children; and normative resources - the four dimensions of sex role orientation-on decision-making authority across the stages of automobile purchasing. The data of 500 demographically heterogeneous married individuals are analyzed by using a Lasso (least absolute shrinkage and selection operator) regression to select variables and to improve the accuracy of prediction and interpretation. The findings reveal that wives' authority is significantly influenced across all stages by their personal income and specific dimensions of their sex role orientation. On the other hand, husbands' authority is not affected by their perception of role norms, but only by their age. Contrary to expectations, the effects of education, occupation, and employment status are not significant in any of the cases, opening a discussion for cross-cultural comparison. The findings are interpreted and transformed into actionable items for managerial implications.
\end{abstract}

Keywords: family purchase decision, consumer behavior, sex role orientation, durable product

\section{Introduction}

Early research identified the power bases determining spousal authority in conflictual decision-making and categorized them as types of resources (Blood \& Wolfe, 1960). Numerous studies reported that comparative socioeconomic resources, such as education, personal income, and occupation status, and the normative context of family interactions, such as spouses' perception of gender role stereotypes are the most potent variables affecting the distribution of authority in consumer durable decisions (Mcdonald, 1980). Decision-making power in a family purchase involving both spouses is a configuration of these sociodemographic resources (Rodman, 1972) and cultural variables based on transgenerational imprints (Scanzoni, 1979; Qualls, 1987).

Significant societal changes have taken place in past decades, promoting egalitarianism and feminist values (Belch \& Willis, 2002). Family decision-making is particularly affected by the transformation of family values. Decisions authority for typically husband-dominated product categories, such as automobiles is

Zsolt Varga, Ph.D. candidate, Graduate School of Economics, Osaka University, Osaka, Japan.

Wirawan Dony Dahana, Ph.D., associate professor, Graduate School of Economics, Osaka University, Osaka, Japan.

Sotaro Katsumata, Ph.D., associate professor, Graduate School of Economics, Osaka University, Osaka, Japan.

Correspondence concerning this article should be addressed to Wirawan Dony Dahana, Graduate School of Economics, Osaka University, 1-7 Machikaneyama, Toyonaka, Osaka 560-0043, Japan. 
increasingly extended to both spouses, because of the spread of egalitarianism and increased involvement of women in activities traditionally associated with males (Qualls, 1987). During the 1980s and 1990s, numerous articles studied the decision power distribution mechanism of Western families; however, very few authors tackled a cross-cultural comparison (Ford, LaTour, \& Henthorne, 1995). Thus, we contend the need to investigate the effect of societal changes on Japanese family decision-making. Our objective was to empirically test the effect of Japanese married individuals' sociodemographic variables and sex role orientation (SRO) perceptions on spousal decision-making authority across the stages of automobile purchasing.

\section{Literature Review}

\section{Marital Decision-Making}

The study of the power relations of the marital couple has been a subject of theoretical research since the 1960s. However, despite increasing and relentless attention from a managerial perspective, theoretical development has stagnated since the 1980s. The concept of decision-making influence in family purchases was ignited in the early 1950s, when Strodtbeck and Bales posited investigating the relative influence of the husband and wife to understand the nature of family decisions. Subsequently, the research developed over the following decades. Many authors took on the challenge to dissect the elements of spousal decision authority (French \& Raven, 1959; Blood \& Wolfe, 1960), sparking the initial idea of family power. One prominent milestone was conceptualized by Davis and Rigaux (1974) who further dissected the mechanism and investigated spousal influence in each stage of the decision-making process. They found that marital influence varies across product categories, stages, and families (Davis, 1976). The mechanism significantly differs for consumer durables compared to frequent, less important purchases. According to traditional family values, the spouse with orchestration power (Safilios-Rothschild, 1970, p. 339) makes important/infrequent decisions and delegates unimportant/time-consuming decisions. In general, theoretical and methodological issues have been tested and further elaborated by numerous scholars. Regarding consumer durables, the specific units of analysis became the marital dyad (Mcdonald, 1980), since the influence of children and other relatives was found to be limited (Spiro, 1983). Cromwell and Olson (1975) conceptualized power from a multidimensional perspective, identifying the three domains of family power as power bases and sources of power, power processes as the interaction techniques of gaining control, and power outcomes as the ultimate decision results. However, family decision-making does not necessary imply conflict (Bahr, 1974; Blalock \& Wilken, 1979), validating the limitation of relevant observation units for power sources and power outcomes.

\section{Power Bases}

The first attempt to identify the sources of spousal decision-making power was based on Blood and Wolfe's (1960) resource theory. In a sociological context, the salient definition of power derives from the discussions of Weber (1947, p. 325). Here, power is "the ability of an individual within a social relationship to carry out his or her will, even in the face of resistance by others". Cromwell and Olson (1975) included the ability to change the behavior of others and other scholars have further refined the definition. More comprehensively, family power is a perceptual, behavioral, multidimensional, and dynamic system property, involving asymmetric relations and reciprocal causation in a sphere of interest (Cromwell \& Olson, 1975; Scanzoni, 1979; Wrong, 1979; Zartman, 1976). Furthermore, the concept of power bases refers to resources (Mcdonald, 1980). 


\section{Comparative Socioeconomic Resources}

According to normative-resource theory (Rodman, 1972), marital power is influenced by comparative socioeconomic resources and subcultural expectations regarding the distribution of spousal power. Comparative socioeconomic resources comprise economic and personally achieved or transgenerational power sources reflecting the relative social competence within the family, such as education, occupation status, or personal income (Mcdonald, 1980). Researchers have observed additional mediating variables to understand the dynamics of authority between spouses, such as the family lifecycle stage, presence/number of children, and numerous demographic variables (Sheth, 1974, Raven, Centers, \& Rodrigues, 1975).

\section{Sex Role Orientation}

Rodman's (1972) cross-cultural study expanded the sources of spousal power to include the cultural and subcultural normative context. Buss and Schaninger (1987) confirmed gender role orientation as one fundamental factor determining household authority. The concept of SRO refers to individual perceptions and attitudes toward gender stereotypes. It is a transgenerational/subcultural imprint prescribing inequalities and roles in a household based on gender (Qualls, 1987). The theory of buying behavior based on role specialization (Davis, 1976) was replicated and extended by Bonfield (1978) who confirmed that the decision-making patterns of couples following traditional family norms significantly differed from those of modern couples. Over the following decades, the intense effect of SRO on spousal authority has been supported in several studies (Chia et al., 1994; Ward \& Sethi, 1986). Scanzoni's (1977; 1979) and Scanzoni and Szinovacz's (1980) treatises are considered major contributions to existing knowledge on the normative context of spousal power relationships, contending that gender role norms are major factors in determining power processes within families. The Scanzoni sex role orientation scale (SSRS) was the first to anatomize the gender role orientation of husbands and wives separately by identifying four underlying dimensions: traditional wife (TW), wife's self-actualization (SA), traditional husband (TH), and husband alterations (HA). To measure SRO, a number of unidimensional measurement techniques have been developed, including the Bem sex role inventory (BSRI) (Bem, 1977) and Osmond and Martin sex role attitude scale (OMSRA) (Osmond \& Martin, 1975), which measure respondents' sex role androgyny and attitudes toward gender roles. However, Qualls (1987) argued that both BSRI and OMSRA provide fairly limited insight compared to the SSRS regarding family purchasing behavior.

\section{Japanese Cultural Considerations}

Despite economic advances and convergence toward a Western corporate culture, the development, structure, and functioning of Japanese society evolved in a significantly different way (Arichi, 1993). The adoption of Confucianism transformed family values into a patriarchic model with strong gender role differentiation, promoting male dominance (Condon, 1984). As Japan transformed into a technologically advanced, highly developed economy during the 1960s and 1970s, the gender-based division of labor became significant and ethics and family lifestyles were adopted in work settings. Because of men's dedication to work, women took control of the management of family expenditure (Sugihara \& Katsurada, 2002), leading to their increased purchase decision power. Despite that modern Japanese society is characterized by strongly differentiated gender roles (Brislin, 1993) and extreme masculinity (Hofstede, 1984; 2010), societal changes are taking place. The evolution of family values remains in the early stage; however, an increasing number of families are starting to explore alternative lifestyles by incorporating egalitarian family values, leading to profound changes in family buying behavior (Ford, LaTour, Honeycutt, \& Voli, 1994). 


\section{Conceptual Framework}

Our proposed conceptual model comprises eight comparative socioeconomic and four normative independent variables. The dependent variable is decision-making authority across the four stages of automobile purchasing (problem recognition, information search, evaluation of alternatives, and final decision). The comparative socioeconomic variables are age, number of married years, educational level, personal income, family income, urban/rural living area, occupational status, and the presence/number of children. The normative power bases are the four dimensions of Scanzoni's SRO: TW, SA, TH, and HA (see Figure 1).

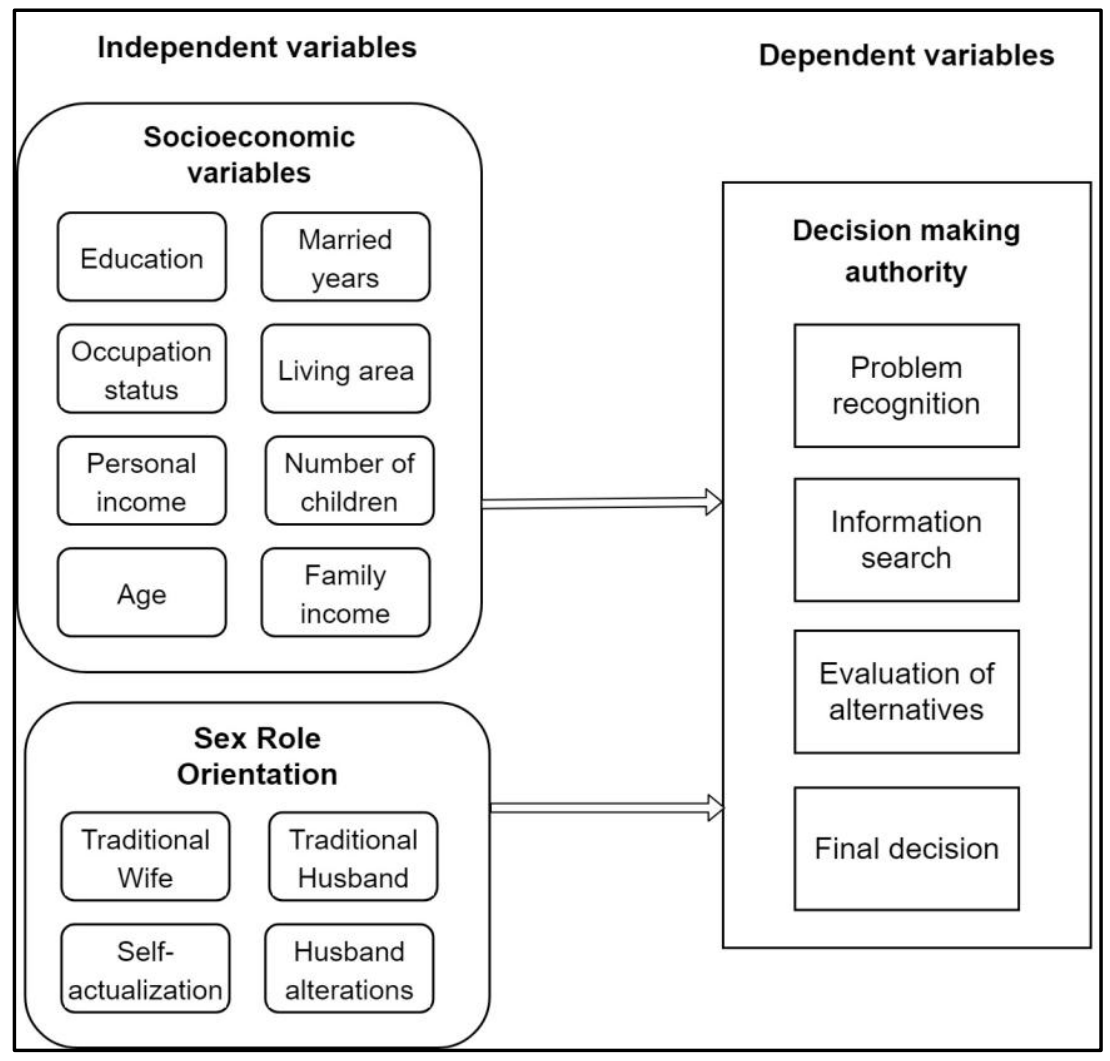

Figure 1. Conceptual framework.

\section{Research Question}

Our research aimed to explore which comparative socioeconomic variables and dimensions of SRO perceptions affect the decision-making authority of Japanese husbands and wives across the stages of automobile purchasing.

\section{Data and Methodology}

Data were gathered from 500 married individuals (250 men and 250 women), using a professional survey company to ensure demographic heterogeneity. The criteria for the survey ensured that all respondents were married, had a driving license, and had purchased a car within the past year. All respondents filled out a questionnaire consisting of $8+21+4$ items. Spouses were asked about their comparative socioeconomic variables, SRO perceptions, and perceived authority across the four stages of their last automobile purchase.

The independent variables were eight socioeconomic variables: age, education, occupation status, personal income, family income, number of married years, living or urban living area, and presence/number of children. 
The four normative variables were the four dimensions of SRO. The dependent variable was perceived decision-making authority across the four stages of automobile buying: problem recognition, information search, evaluation of alternatives, and final decision.

Scanzoni's SSRO scale (Scanzoni, 1979) has been employed to measure individual perceptions of SRO. The measurement technique is the most widely used gender role attitude measurement scale in family buying behavior studies and has been validated in numerous studies (Qualls, 1987; Buss \& Schaninger, 1987). The SSRO consists of 21 Likert-scaled batteries (1-5) that tap into four underlying SRO dimensions: TW, TH, SA, and HA. TW and SA measure respondents' attitude toward prescribed roles and the gender roles of women. TH and HA measure the support or disapproval of the traditional, patriarchal family style regarding husbands' behavior. TH and TW measure the traditional perceptions of female and male roles, while SA and HA focus on attitude toward a modern family style, in which women depart from the housewife lifestyle and pursue personal life goals. Here, husbands assist their wives' ambitions by participating more in child-raising and household chores. Accordingly, high scores on TH and TW mean that respondents' perceptions are traditional, while high scores on SA and HA evince modern values.

A Lasso (least absolute shrinkage selection operator) regression was adopted for the analysis, because the method performs variable selection and regularization for improved interpretability and prediction accuracy. Furthermore, this measurement technique is especially functional in the case of multicollinearity and a large number of independent variables.

\section{Results}

The respondent population was demographically heterogeneous and accurately represents the Japanese population according to the data provided by the Statistical Bureau of Japan (2018).

To test the reliability of the survey, a confirmatory factor analysis was performed for the SRO items. The results were consistent with the findings of the original author (Scanzoni, 1979). Cronbach's alpha coefficients for TW, SA, TH, and HA were $0.47,0.76,0.84$, and 0.72 respectively, validating three of the four constructs. The Cronbach's alpha value of the TW dimension was lower than 0.7 ; however, to remain consistent with the original author's work, we retained the construct. The SRO scores were obtained by averaging the score of the items in each dimension. The summary statistics of the reliability tests are provided in the Appendix.

Eight research models were constructed for the analysis. The effects of the independent variables on decision-making authority were measured across the four stages of the purchase for husbands and wives separately (see Table 1).

Table 1

Research Models

\begin{tabular}{lll}
\hline Models & Dependent variable (authority) & Sample \\
\hline Case 1 & Problem recognition & Male sample \\
Case 2 & Information search & Male sample \\
Case 3 & Evaluation of alternatives & Male sample \\
Case 4 & Final decision & Male sample \\
Case 5 & Problem recognition & Female sample \\
Case 6 & Information search & Female sample \\
Case 7 & Evaluation of alternatives & Female sample \\
Case 8 & Final decision & Female sample \\
\hline
\end{tabular}


The effects of the eight comparative socioeconomic variables and four dimensions of SRO (TW, SA, TH, and HA) were tested using a Lasso regression (see Table 2). The value of the tuning parameter $(\lambda)$ was obtained through a cross-validation. In all eight cases, the value of $\lambda$ providing the minimum mean cross-validated error was selected. To test the statistical significance of the variables, a bootstrap-based procedure was conducted with 1,000 iterations for each model, as suggested by the original author of the Regression Shrinkage and Selection, via the Lasso (Tibshirani, 1996).

Table 2

Results of the Lasso

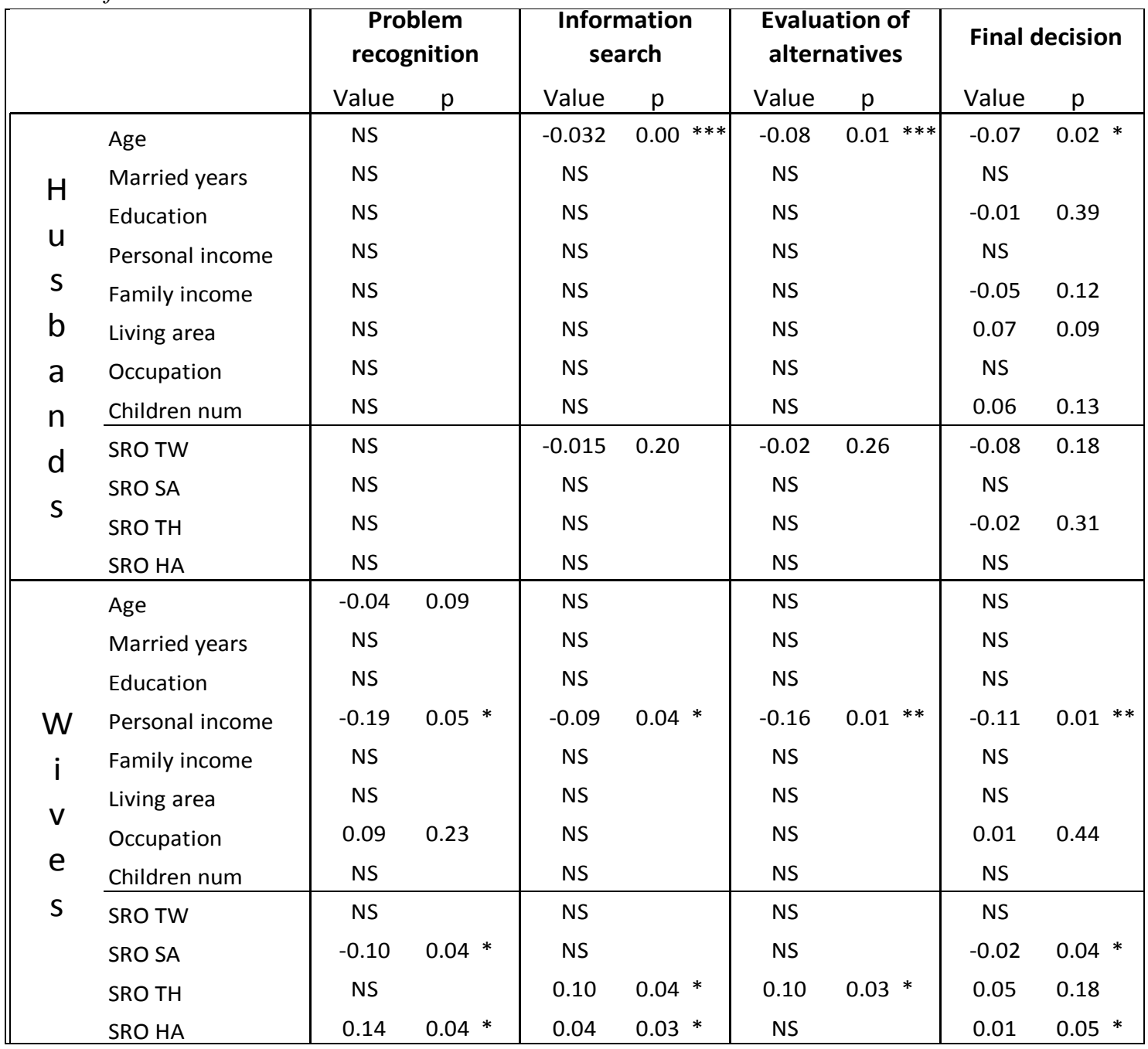

Notes. Not significant, ${ }^{*} p<0.05 ;{ }^{* *} p<0.01 ;{ }^{* * *} p<0.001$.

Regarding husbands, in Case 1, the analysis eliminated all independent variables. In Cases 2 and 3, age and the SRO TW dimension were selected by the Lasso. Age was strongly statistically significant. In Case 4, age, education, living area, the presence/number of children, and the two SRO dimensions TW and HA were selected by the regression analysis; however, only age was found to be significant.

Regarding wives, in Case 5, age, personal income, occupation status, and the two SRO dimensions SA and HA were selected, and personal income and the two SRO items were statistically significant. In Case 6, 
personal income, SRO TH, and SRO HA were selected and confirmed as significant. Personal income and SRO TH were selected and significant in Case 7. At the final decision stage, personal income, occupation status, and the three SRO dimensions SA, TH, and HA were selected by the analysis. Personal income and the SRO dimensions SA and HA were confirmed as statistically significant.

\section{Discussion and Interpretation}

According to the results, comparative socioeconomic variables and SRO perceptions affect men and women in a significantly different way.

\section{Husbands' Authority}

Husbands' decision-making authority was not affected by their SRO and only by their age. From the information search stage until the final decision, male respondents' decision-making authority increased with age. This result can be attributed to the fact that the younger generation of men follows a more modern family lifestyle with an egalitarian mindset, while the older generation relies on more traditional family values, in which husbands possess orchestration power (Safilios-Rothschild, 1970) regarding family purchases. The Lasso selected education, family income, living area, number of children, and the two SRO dimensions TW and TH; however, the levels of statistical significance were insignificant.

\section{Wives' Authority}

Wives' decision-making authority is influenced by their SRO perceptions and personal income across all stages. Women with a high income tend to possess significantly higher authority at all stages. Women who distance themselves from traditional beliefs regarding self-actualization and pursue their personal achievements outside the home tend to take a greater part in the problem recognition and final decision stages. Consistent with expectations, women who believe in traditional husband norms tend to take a lesser part in both the information search and evaluation of alternatives stages. Wives with modern perceptions of HA tend to possess higher authority in almost all stages, excepting the evaluation of alternatives.

\section{Effect of Comparative Socioeconomic Variables on Decision-Making Authority}

The results reveal that the distribution of decision-making authority between Japanese spouses is primarily affected by two socioeconomic variables: age in the case of men and personal income for women. Contrasting expectations based on previous findings (Safilios-Rothschild, 1970; Holman \& Burr, 1980), education, family income, living area, occupation status, and the presence/number of children do not affect the distribution of authority between husbands and wives. The results reveal that instead of the family lifecycle proposed by Davis and Rigaux (1974), husbands' age affects family decision authority among Japanese marital couples.

\section{Effect of Sex Role Orientation on Decision-Making Authority}

Three of the four SRO dimensions (SA, TH, and HA) were confirmed to significantly affect the behavior of wives. Wives with more modern SRO perceptions pursue egalitarianism and shared authority across all stages of the buying process. On the other hand, husbands' decision-making authority is insensitive to their SRO perceptions across all stages.

The dissimilarity of these results with those of prior research can be explained by the cultural differences between Japanese society and Western countries, and the highly gender-specific product category, which forms part of the cultural perceptions of Japanese society. 


\section{Implications}

\section{Theoretical Implications}

The theory of Western studies seems to partially hold for Japanese society. However, the insignificant effect of education, occupation status, and family income on decision-making authority leads to the assumption that the structure of Japanese family decision-making differs from that of Western families. Applying the power bases specified in the original normative resource theory might lead to imprecise interpretations of Japanese consumer behavior. Therefore, we propose that the elements of comparative socioeconomic and cultural resources be selected and applied considering the cultural background of the sample population. The factors determining spousal authority in the case of consumer durables might benefit from a more in-depth and cross-cultural analysis. Such comparison could provide more structured and comprehensive insights into family buying behavior and a number of mediating variables might be discovered through exploratory research based on cultural considerations and qualitative approaches.

\section{Managerial Implications}

The results highlight marketing implications for practitioners, which can be extended to the entire Japanese population. For elderly couples, marketing activities should target the men. The strong effect of SRO and personal income on wives' decision-making authority indicates that marketing campaigns and sales tools should focus on wives with relatively high income and a modern SRO, and target them at all stages of the purchase.

\section{References}

Arichi, T. (1993). Kazoku wa kawatta ka (Has families changed?). Tokyo: Yūhikaku.

Bales, R. F., \& Strodtbeck, F. L. (1951). Phases in group problem-solving. The Journal of Abnormal and Social Psychology, 46(4), 485.

Belch, M. A., \& Willis, L. A. (2002). Family decision at the turn of the century: Has the changing structure of households impacted the family decision-making process? Journal of Consumer Behaviour, 2(2), 111-124.

Bem, S. L. (1977). Bem sex role inventory (BSRI). The 1977 Annual Handbook for Group Facilitators, pp. 83-85.

Blalock, H. M., \& Wilken, P. H. (1979). Intergroup processes: A micro-macro perspective. New York: Free Press.

Blood Jr, R. O., \& Wolfe, D. M. (1960). Husbands and wives: The dynamics of family living. Oxford, England: Free Press Glencoe.

Bonfield, E. H. (1978). Perception of marital roles in decision processes: Replication and extension. In K. Hunt and A. Abor (Eds.), NA-Advances in consumer research (Volume 5, pp. 300-307). MI: Association for Consumer Research.

Brislin, R. (1993). Understanding culture's influence on behavior. Orlando, FL: Harcourt Brace Jovanovich.

Bühlmann, P., Meier, L., \& van de Geer, S. (2014). Discussion: A significance test for the lasso. The Annals of Statistics, 42(2), 469-477.

Buss, W. C., \& Schaninger, C. M. (1987). An overview of dyadic family behavior and sex roles research: A summary of findings and an agenda for future research. In M. Houston (Ed.), Review of marketing (pp. 293-324). Chicago: American Marketing Association.

Chia, R. C., Chong, C. J., \& Cheng, B. S. (1987). Relationship of modernization and marriage role attitude among Chinese college students. Journal of Psychology, 120(6), 599-605.

Chia, R. C., Wuensch, K. L., Childers, J., \& Chuang, C. (1994). A comparison of family values among Chinese, Mexican, and American college students. Journal of Social Behavior and Personality, 9(2), 249.

Condon, J. C. (1984). With respect to the Japanese: A guide for Americans. Yarmouth, ME: Intercultural Press.

Cromwell, R. E., \& Olsen, D. H. (1975). Power in families. Oxford, England: Sage.

Davis, H. L., \& Rigaux, B. P. (1974). Perception of marital roles in decision processes. Journal of Consumer Research, 1(1), 51-62. 
Davis, H. L. (1976). Decision-making within the household. Journal of Consumer Research, 2(4), 241-260.

Ford, J. B., LaTour, M. S., \& Henthorne, T. L. (1995). Perception of marital roles in purchase decision processes: A cross-cultural study. Journal of the Academy of Marketing Science, 23(2), 120-131.

Ford, J. B., LaTour, M. S., Honeycutt Jr, E. D., \& Voli, P. K. (1994). Perceptions of sex role portrayals in advertising: A comparison of business students in the United States, Japan, Thailand and New Zealand. Asian Journal of Marketing, 2(December), 21-36.

French, J., Jr., \& Raven, B. (1959). The bases of social power. In A. Arbor (Ed.), Studies in social power (pp. 150-165). MI: Institute for Social Research.

Hofstede, G. (1984). Cultural dimensions in management and planning. Asia Pacific Journal of Management, 1(2), 81-99.

Hofstede, G. (2010). National cultural dimensions. Retrieved December 16, 2017, from http://www.geert-hofstede.com/

Holman, T. B., \& Burr, W. R. (1980). Beyond the beyond: The growth of family theories in the 1970s. Journal of Marriage and the Family, 42(4), 729-741.

McDonald, G. W. (1980). Family power: The assessment of a decade of theory and research, 1970-1979. Journal of Marriage and the Family, 42(4), 841-854.

Osmond, M. W., \& Martin, P. Y. (1975). Sex and sexism: A comparison of male and female sex-role attitudes. Journal of Marriage and the Family, 37(4), 744-758.

Qualls, W. J. (1987). Household decision behavior: The impact of husbands' and wives' sex role orientation. Journal of Consumer Research, 14(2), 264-279.

Raven, B. H., Centers, R., \& Rodrigues, A. (1975). The bases of conjugal power. In R. S. Cromwell and D. H. Olson (Eds.), Power in families (pp. 217-232). New York: Wiley.

Rodman, H. (1972). Marital power and the theory of resources in cultural context. Journal of Comparative Family Studies, 3(1), 50-69.

Rollins, B. C., \& Bahr, S. J. (1976). A theory of power relationships in marriage. Journal of Marriage and the Family, 38(4), 619-627.

Safilios-Rothschild, C. (1970). The study of family power structure: A review 1960-1969. Journal of Marriage and Family, 32(4), 539-552.

Scanzoni, J. (1977). Changing sex roles and emerging directions in family decision-making. Journal of Consumer Research, 4(3), 185-188.

Scanzoni, J. (1979). Social processes and power in families. In W R. Burr, R. Hill, F. I. Nye, and I. L. Reiss (Eds.), Contemporary theories about the family (Vol. 1, pp. 295-316). New York: Free Press.

Scanzoni, J. H., \& Szinovacz, M. E. (1980). Family decision-making: A developmental sex role model. Beverly Hills, Calif.: Sage Publications.

Schaninger, C. M., Buss, W. C., \& Grover, R. (1982). The effect of sex roles on family finance handling and decision influence. In B. Walker et al. (Eds.), An assessment of marketing thought and practice (pp. 43-46). Chicago: American Marketing Association.

Sheth, J. N. (1974). A theory of family buying decisions. In J. N. Sheth (Ed.), Models of buyer behavior: Conceptual, quantitative, and empirical (pp.17-33). New York: Har per and Row.

Spiro, R. L. (1983). Persuasion in family decision-making. Journal of Consumer Research, 9(4), 393-402.

Statistical Bureau. (2018). Chapter 2 Population and Households. Japan Statistical Yearbook 2018. Ministry of Internal Affairs and Communications. Retrieved from: https://www.stat.go.jp/english/data/nenkan/67nenkan/1431-02.html

Sugihara, Y., \& Katsurada, E. (2002). Gender role development in Japanese culture: Diminishing gender role differences in a contemporary society. Sex Roles, 47(9-10), 443-452.

Tibshirani, R. (1996). Regression shrinkage and selection via the lasso. Journal of the Royal Statistical Society, Series B (Methodological), 267-288.

Tibshirani, R., Wainwright, M., \& Hastie, T. (2015). Statistical learning with sparsity: The lasso and generalizations. Boca Raton, FL, Chapman and Hall/CRC.

Ward, C., \& Sethi, R. R. (1986). Cross-cultural validation of the Bem sex role inventory: Malaysian and South Indian research. Journal of Cross-Cultural Psychology, 17(3), 300-314.

Weber, M. (1947). The theory of economic and social organization. (A. M. Henderson and T. Parsons. Trans.). New York: Oxford University Press.

Wrong, D. H. (1979). Power: Its forms. bases and uses. New York: Harper and Row.

Zartman, I. W. (1976). The analysis of negotiation: The 50\% solution. New York: Anchor Books. 


\section{Appendix}

Table A.1

Summary Statistics of the Confirmatory Factor Analysis

\begin{tabular}{llllllll}
\hline & \multicolumn{3}{c}{} & \multicolumn{3}{c}{ Standardized covariance } \\
\cline { 2 - 7 } & ALPHA & CR & AVE & TW & SA & HA & TH \\
\hline TW: Traditional wife & 0.844 & 0.847 & 0.414 & 1.000 & & & \\
SA: Wife self-actualization & 0.468 & 0.426 & 0.212 & -0.144 & 1.000 & & 1.000 \\
HA: Husband alteration & 0.764 & 0.762 & 0.367 & -0.271 & 0.707 & 0.230 & 1.000 \\
TH: Traditional husband & 0.720 & 0.721 & 0.564 & 0.593 & 0.263 & RMSEA \\
Overall fitness & CHISQ & P-Value & GFI & AGFI & CFI & R \\
& 1392.6 & 0.000 & 0.778 & 0.720 & 0.706 & 0.115 \\
\hline
\end{tabular}

Notes. $N=500$; ALPHA: Cronbach's alpha coefficient; CR: Composite reliability; AVE: Average variance extracted; CHISQ: model chi square value; GFI: Goodness of fit index; AGFI: Adjusted goodness of fit index; CFI: Comparative fit index; RMSRA: Root means squared error of approximation. 